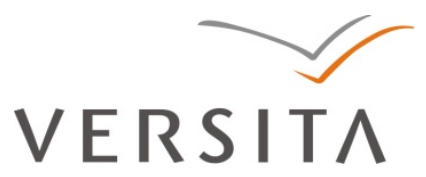

BULGARIAN ACADEMY OF SCIENCES

CYBERNETICS AND INFORMATION TECHNOLOGIES • Volume 13, Special Issue

Sofia • 2013

Print ISSN: 1311-9702; Online ISSN: 1314-4081

DOI: 10.2478/cait-2013-0044

\title{
Evaluation of Strategies in the Process of China's City Informatization Using the AHP Method
}

\author{
Ke Xinsheng, Qi Sun
}

School of Economics and Management, Beijing Jiaotong University, Beijing, China,100044 Emails:12120659@bjtu.edu.cn xske@bjtu.edu.cn

\begin{abstract}
Informatization is the new power for urban management innovation -- the tools to enhance the quality of life for citizens and the new ways to improve government services. However, there are many problems in the informatization construction process of the Chinese cities, such as poor level design, hard effects than to soft, the lack of features, poor e-government function and information collaboration. This paper analyzes the problems in the informatization construction of Chinese cities, combined with advances in information network technology, social needs, and some city informatization instances, proposes development tactics of Chinese city informatization. Ultimately, AHP and ISM has been used to analyze the numerical value of different plans, carrying out the best plan under the criterion.
\end{abstract}

Keywords: City informatization, strategy hierarchy model assess.

\section{Introduction}

By the 1990-ies, along with the popularization and application of information and network technology in the world, the city informatization construction is regarded with great importance by the government and the public. In [1] $\mathrm{C} h$ e $\mathrm{n}$ has elaborated that the vitality, the attraction, radiation, and the level of the city's 
management did not rely on the size of the jurisdiction, but relied on capital, information services and technology innovation in new economic society. In the 21-st century, with Internet applied largely and 3G, the physical network appearing as the emerging techniques, the informatization of the city has a direct impact on competitiveness. Only by relying on advanced network infrastructure for information cooperation, carrying out e-Government actively, e-Commerce and other emerging business, service demands can be dealt appropriately in the enterprises and public, which enhances the central role of the city, as well as increases the contacts among cities.

$\mathrm{T}$ o $\mathrm{n} g$ [10] shows that providing finance, information, science, technology, culture and other services to the surrounding, positively makes this city the core of the regional economy, which increases the city's radiation, and attracts talents, technology and funds at the same time. City informatization is the core of regional information and an important part of country's informatization, but there are also many errors in China's current city informatization construction. According to the city's own economic strength, industry characteristics, human resources, geographical and cultural characteristics, how to formulate tactics and modes appropriately in city informatization development, appears particularly important [12].

\section{Development situation}

In developed countries, such as USA, Canada and, etc., informatization has walked into every corner of the city, especially the public service. New York built the nation's largest public health system and came to be a pioneering leader in clinical informatics. L e vis s [6] proposed collaboration between clinical and information system leaders creating a technology tool that enables the redesign and improvement of the clinical care.

In the past few decades some developing countries have also grasped the opportunities of informatization and changed the nation and region's economic and social outlook. K i m and C h o [5] claimed in that the OPEN (Online Procedures ENhancement from civil application) system in the Seoul metropolitan government of South Korea has helped to achieve transparency in the civil administration by preventing unnecessary delays and unjust handling of civil affairs on the part of civil servants.

For China the field for informatization is not the same but the manner is extremely similar. P e $\mathrm{n}$ g [2] gives a detailed portrait of the digital city Shanghai project in four parts: spatial data infrastructure, city informatization Shanghai city grid, and Shanghai Logistics information platform. Then L u [7] provides the strategies and recommendations, to speed up the development of "digital Hubei", which includes digital technology, the top-level design of e-Government participation of the government, business and academia. 


\section{The problems of city's informatization construction in current China}

Data from [14] confirmed that relying on digital tools, up to the end of 2011, more than 120 cities constructed the city's management information system, more than 400 cities built a real estate management information system, over 100 cities built a comprehensive and professional pipe network management system, and more than 100 cities were building an information system based on space. Information has been involved in urban planning, management, economy, life, culture and other aspects.

Overall, most of China's large and medium cities have established the action target and implementation plan of informatization. Additionally, certain achievements have been made because of the different characteristics in practice, but mostly since the effect of the city information is poor, the main problems are as follows:

First, in China, city informatization construction was mainly leaded by all levels of government, which lacks a scientific and practical general frame and operation mode of the city informatization construction, and the top-level design is poor. The function of China's city government informatization management currently is scattered, with repetitions and crossing. In other words, different departments stress their own interest. Centralized, unified, coordinated and powerful management system which has a serious impact on the advancement of city informatization construction is needed.

Second, while the infrastructure of a large-scale network is being constructed in the city, ignoring the information resources development, management, sharing and using, there is present a picture of hard efforts other than isolated information island. Currently, many domestic cities pursuit a broadband network so blindly that all kinds of sites are established as soon as possible, which resulted in a huge cost in building networks and various websites ignoring the construction of large-scale information resources. Due to insufficient, useful information, the website becomes a "bare network", that did not attract the "eyeball". K e [4] proposed, that having no supports from various information resources, the business information systems running on the network, which cannot be a good solution to real business problems, are just like in the forest.

Third, paying attention to the techniques, and looking at the reform of the city's management and process of the reconstruction with contempt, is "put the cart before the horse". In order to adapt to the development of informatization, it is imperative to perfect the management and the mechanism reform, since the informatization is not only a new technological revolution, but a management revolution. Historical experience indicates that every time a technological revolution appears, the primary task is to weed out the old management system and promote technological revolutions and the vitality of innovations in an enterprise.

Fourth, the implementation of the e-Government affairs function is insufficient, the operability is weak and the inter-departmental information coordination is poor, which leads to poor e-Government coordination between departments. Combined with the development of Internet to meet the needs of the 
citizens' right to know, with the central government's strong encouragement, e-Government has become the main content of the information technology of the central government departments. Through understanding Internet business gradually, the managers of the government departments have a certain understanding for the role and business model of the e-Government, but there are still some irrational internal processes, "barren" information resources and deficiencies of a maintenance mechanism.

Fifth, there is no light of its own characteristics in city informatization in the feasibility analysis, which seems to be blind development, and copy the mode from the domestic and international economic developed cities, no features, lack of personality, and a heavy financial and management pressures. The city's construction of digital tools has shown unprecedented enthusiasm. Beijing is to build "digital Beijing", Shanghai is to build an "information harbor", subsequently Chengdu and Qingdao put forward "digital Chengdu”, "digital Qingdao”, Handan is "number 1115", more and more cities come into this upsurge influence - proposed similar plans of a digital city, according to [9] carried by a system application office. Analyzing these plans carefully, it is not too hard to find that most of them are hard to be copied.

\section{The strategies of city informatization in China}

It has been urgent for the city to focus on its own features and characteristics so that the general public can increasingly feel the benefits of information technology, which will also be the basis for a big step forward. What is more, emphasizing the city's information resources of development and utilization in deep lever, and constructing informatization on e-Government affairs and social service sector, is the next step of the construction and development of the city's information [3]. It is the city's information platform forming parallel patterns that makes industrialization in a green, smart direction and makes the city work more efficiently and look more beautiful, which is a promotion strategy for China's city informatization [13]. Based on the experience of the city in decades in the development of information technology, the strategies of China's city informatization are put forward as follows.

\subsection{Choosing a particular industry or field as information entry point}

Cites have so many differences in level, function, size and development that the ideal model in city's information technology may not be applied to other cities. China's east and west, north and south on city's development are uneven and different, so the cities should adhere to the principle of "local conditions" and "realistic": Giving a full play to the comparative advantage of the local resource, selecting the urgent need and the quick impact, choosing the field or industry driven by a strong attention, as the breakthrough point, pushing the city's comprehensive development and social progress, taking the path of the local road with its characteristics while promoting informatization [11]. 
Specifically, Hainan is striving to develop its informatization along with the new policy issued by the state - international tourism island. Choosing tourism as a focus helps it to develop related fields of informatization and bring in several business opportunities (Table 1) [17]. In The 12th Five-year Plan of the Capital Economy and Social Development for Hainan Province [17], it can be seen that after years of exploration, Hainan has found itself a special way for developing.

Table 1. Analysis on the development of informatization in Hainan province between 2011- 2015

\begin{tabular}{|c|c|}
\hline Status & $\begin{array}{l}\text { Promotion effect of the traditional industry is obvious. } \\
\text { Scale of this island is small, market demand and insufficient factors, such as } \\
\text { government investment ability is limited }\end{array}$ \\
\hline Superiority & Location, Environment, Infrastructure, Policy advantage \\
\hline Strategy & $\begin{array}{l}\text { Wisdom tourism island engineering, industry demonstration base, e-Government, } \\
\text { information of agriculture engineering, intelligent traffic engineering, digital } \\
\text { medical treatment, coconut island card, electronic commerce engineering, wireless } \\
\text { engineering, digital "south sea” project in Hainan, promotion information literacy } \\
\text { project }\end{array}$ \\
\hline
\end{tabular}

4.2. Choosing an area in the city, then a public service of the government and agencies to carry out the implementation of information technology demonstration, step by step

The developments of the various regions in the city generally have their own priorities, the services awareness of many government departments with existing information resources is uneven, the business processes of regulating the social attention is not the same, and the quality of the personnel is also different. In this situation, you can choose the area which has more strength, characteristics and resource-based sectors as a pioneer in city informatization to drive the development as a whole.

For example, Zhongguancun, in Beijing, is a high-tech industrial belt which focuses on development of an information network with huge capacity in network facilities and PC application. Zhongguancun Science and Technology Park was chosen as the demonstration site for the network office of city informatization in Beijing. With the goal to be a scientific and technological innovation center with global influence, it runs good in high level of information, so that the following public administrations can create favorable conditions. Zhongguancun Planning Outline of National Innovation Demonstration Zone Development (2011-2020) presents the developing process of it in these years (Table 2).

\subsection{Reasonably planning the city government task}

The government which can control the overall plan in economically developed cities should not be involved in details of the information technology or dilute the significance of the government too much to encourage the enterprises to have the courage to bring forth new ideas or be engaged actively in the construction and practice of the city informatization. However, as for an enterprise, the less economically developed city it is located in, the weaker the driving force will be.

Currently, this strategy for division has emerged in some cities and provinces, such as Shenzhen which belongs to the former and Shijiazhuang that belongs to the 
latter category. With the aid of the forces, arousing the enthusiasm to the maximum extent is an efficient way to speed up the construction of the city's information under the conditions of market economy. The amount of Guangdong province is more than twice the amount of Hebei province and both of them keep an amazing speed in increasing. However, it is not hard to notice, that among all the projects whose invest amounts have reached 5 million, compared with Hebei Province, Guangdong Province has a huge economic advantage, has a role that cannot be ignored in the informatization construction.

Table 2. The developing process of Zhongguancun

\begin{tabular}{|c|c|}
\hline Time & History \\
\hline Early 1980s & Zhongguancun firstly appeared as an electronic street \\
\hline May 1988 & $\begin{array}{c}\text { the state council approved that the new technology industrial development } \\
\text { experimental area, the prototype of Zhongguancun science park, was set up } \\
\text { in Beijing }\end{array}$ \\
\hline March 13, 2009 & $\begin{array}{c}\text { the state council approved the construction of Zhongguancun national } \\
\text { innovation demonstration zone and expect to build Zhongguancun into a } \\
\text { science and technology innovation center with global influence, which is } \\
\text { China's first national independent innovation demonstration area }\end{array}$ \\
\hline October 13, 2012 & $\begin{array}{c}\text { the state council agreed to adjust the space of Zhongguancun national } \\
\text { innovation demonstration zone, increased from original 1zone with 10 parks } \\
\text { to one zone with 16 parks }\end{array}$ \\
\hline
\end{tabular}

4.4. Constraining the construction of the network and information resources actively

It will not only provide a safe and fast interface for exchanging, transferring and sharing information, but also ensure the multi-perspective deep-seated development and application of the information resources, lower the cost of information technology. It has been told by Beijing economic and information technology commission in Beijing Informatization Annual Report 2010 [15] that by comparing some of their conditions, China's provincial government websites are marked by a score. The quality of the information resources is the key issue in both information construction and is the place with a huge foreign information gap [16]. Beijing as an easy access to the information construction leaping in the development in recent years makes remarkable achievements.

4.5. Promoting informatization by public awareness and skills, with some impacts of the large public events held in the city

With the wake of two kinds of models of thinking, namely a positive challenge and passive treatment, there will be two different effects. On one hand, the ordinary urban residents can take advantage of some large public events held in the city - the marketing adjunct - as a tool. On the other hand, popularizing the knowledge of informatization and the use of information network technology can make more changes to attract the public to expand the impact and enhance the general public's awareness and skills. 
For example, with the opportunity to host the Olympic Games in 2008 in Beijing, no matter of the business activity in Olympic venues ,the information service related to the advanced wireless network technology or the application of online ticketing system is promoting the construction of "high-tech Olympics" concept. In terms of e-Government, the electronic government website (http://eservice.beijing.gov.cn) meets the demands of the related services both home and abroad the Olympic Games. Now under the background of "science and technology Olympics" activities will promote the construction of informatization in Beijing thorough a popular feeling.

\section{Evaluating the five plans by using the AHP method}

AHP mentioned in this paper is a method which is a combination of qualitative and quantitative evaluation, and is systematic and hierarchical analysis. According to Peng Yunfei it is a kind of scientific way of thinking, which will take the subjective judgment and experience of the decision maker into the model, then identify the utility level of each strategy [8]. So rather than prescribing a "correct" decision, the AHP helps the decision makers find the one that best suits their needs and their understanding of the problem.This paper will use the AHP method as follows:

\subsection{Establishing the hierarchy model}

To assume the hierarchical structure model here from the top to the bottom layer target level, criterion level and scheme are used. After combining the characters of city informatization and the suggestions of the experts, the level of city informatization is regarded as the general target. Taking the cost and utility as the criterion level, time consuming, human, capital, benefited users, convenience, upgrading as the second index, refining can be finished (Fig. 1).

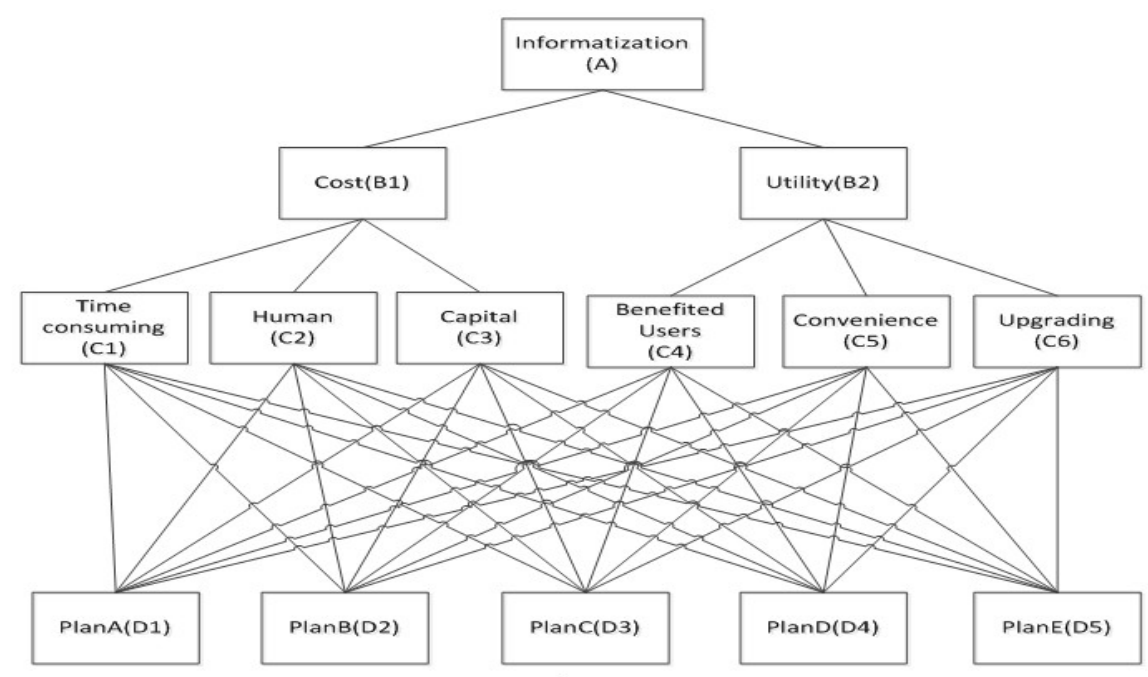

Fig. 1. City informatization evaluation index system of the hierarchical structure 


\subsection{Establish the judgment matrix}

In the primary index of the criterion level, cost and utility both take an important place, therefore their weights are the same, 0.5. According to Fig. 1, we invite five experts to do research, that is to compare the elements of neighboring layers in the model in order to get 8 judgment matrixes (Tables 3-10).

Table 3. $\mathrm{B}_{1}$-C judgment matrix
\begin{tabular}{|c|c|c|c|}
\hline $\mathrm{B}_{1}$ & $\mathrm{C}_{1}$ & $\mathrm{C}_{2}$ & $\mathrm{C}_{3}$ \\
\hline $\mathrm{C}_{1}$ & 1 & 4 & 3 \\
\hline $\mathrm{C}_{2}$ & $1 / 4$ & 1 & $1 / 3$ \\
\hline $\mathrm{C}_{3}$ & $1 / 3$ & 3 & 1 \\
\hline
\end{tabular}

Table 4. $\mathrm{B}_{2}$-C judgment matrix

\begin{tabular}{|c|c|c|c|}
\hline $\mathrm{B}_{2}$ & $\mathrm{C}_{4}$ & $\mathrm{C}_{5}$ & $\mathrm{C}_{6}$ \\
\hline $\mathrm{C}_{4}$ & 1 & 5 & $1 / 3$ \\
\hline $\mathrm{C}_{5}$ & $1 / 5$ & 1 & $1 / 7$ \\
\hline $\mathrm{C}_{6}$ & 3 & 7 & 1 \\
\hline
\end{tabular}

Table 5. $\mathrm{C}_{1}$-D judgment matrix

\begin{tabular}{|c|c|c|c|c|c|}
\hline $\mathrm{C}_{1}$ & $\mathrm{D}_{1}$ & $\mathrm{D}_{2}$ & $\mathrm{D}_{3}$ & $\mathrm{D}_{4}$ & $\mathrm{D}_{5}$ \\
\hline $\mathrm{D}_{1}$ & 1 & 3 & $1 / 5$ & 3 & $1 / 5$ \\
\hline $\mathrm{D}_{2}$ & $1 / 3$ & 1 & $1 / 7$ & $1 / 3$ & $1 / 7$ \\
\hline $\mathrm{D}_{3}$ & 5 & 7 & 1 & 5 & $1 / 3$ \\
\hline $\mathrm{D}_{4}$ & $1 / 3$ & 3 & $1 / 5$ & 1 & $1 / 7$ \\
\hline $\mathrm{D}_{5}$ & 5 & 7 & 3 & 7 & 1 \\
\hline
\end{tabular}

Table 6. $\mathrm{C}_{2}$-D judgment matrix

\begin{tabular}{|c|c|c|c|c|c|}
\hline $\mathrm{C}_{2}$ & $\mathrm{D}_{1}$ & $\mathrm{D}_{2}$ & $\mathrm{D}_{3}$ & $\mathrm{D}_{4}$ & $\mathrm{D}_{5}$ \\
\hline $\mathrm{D}_{1}$ & 1 & 3 & $1 / 5$ & $1 / 3$ & 5 \\
\hline $\mathrm{D}_{2}$ & $1 / 3$ & 1 & $1 / 7$ & $1 / 5$ & 3 \\
\hline $\mathrm{D}_{3}$ & 5 & 7 & 1 & 3 & 7 \\
\hline $\mathrm{D}_{4}$ & 3 & 5 & $1 / 3$ & 1 & 7 \\
\hline $\mathrm{D}_{5}$ & $1 / 5$ & $1 / 3$ & $1 / 7$ & $1 / 7$ & 1 \\
\hline
\end{tabular}

Table 7. $\mathrm{C}_{3}$-D judgment matrix

\begin{tabular}{|l|l|l|l|l|l|}
\hline $\mathrm{C}_{3}$ & $\mathrm{D}_{1}$ & $\mathrm{D}_{2}$ & $\mathrm{D}_{3}$ & $\mathrm{D}_{4}$ & $\mathrm{D}_{5}$ \\
\hline $\mathrm{D}_{1}$ & 1 & $1 / 3$ & $1 / 5$ & 3 & 5 \\
\hline $\mathrm{D}_{2}$ & 3 & 1 & $1 / 3$ & 3 & 7 \\
\hline $\mathrm{D}_{3}$ & 5 & 3 & 1 & 7 & 7 \\
\hline $\mathrm{D}_{4}$ & $1 / 3$ & $1 / 3$ & $1 / 7$ & 1 & 3 \\
\hline $\mathrm{D}_{5}$ & $1 / 5$ & $1 / 7$ & $1 / 7$ & $1 / 3$ & 1 \\
\hline
\end{tabular}

Table 8. $\mathrm{C}_{4}$-D judgment matrix

\begin{tabular}{|c|c|c|c|c|c|}
\hline $\mathrm{C}_{4}$ & $\mathrm{D}_{1}$ & $\mathrm{D}_{2}$ & $\mathrm{D}_{3}$ & $\mathrm{D}_{4}$ & $\mathrm{D}_{5}$ \\
\hline $\mathrm{D}_{1}$ & 1 & $1 / 5$ & 5 & $1 / 3$ & 3 \\
\hline $\mathrm{D}_{2}$ & 5 & 1 & 7 & 3 & 5 \\
\hline $\mathrm{D}_{3}$ & $1 / 5$ & $1 / 7$ & 1 & $1 / 7$ & $1 / 3$ \\
\hline $\mathrm{D}_{4}$ & 3 & $1 / 3$ & 7 & 1 & 5 \\
\hline $\mathrm{D}_{5}$ & $1 / 3$ & $1 / 5$ & 3 & $1 / 5$ & 1 \\
\hline
\end{tabular}


Table 9. $\mathrm{C}_{5}$-D judgment matrix

\begin{tabular}{|c|c|c|c|c|c|}
\hline $\mathrm{C}_{5}$ & $\mathrm{D}_{1}$ & $\mathrm{D}_{2}$ & $\mathrm{D}_{3}$ & $\mathrm{D}_{4}$ & $\mathrm{D}_{5}$ \\
\hline $\mathrm{D}_{1}$ & 1 & $1 / 5$ & 3 & $1 / 3$ & 3 \\
\hline $\mathrm{D}_{2}$ & 5 & 1 & 7 & 3 & 5 \\
\hline $\mathrm{D}_{3}$ & $1 / 3$ & $1 / 7$ & 1 & $1 / 5$ & $1 / 3$ \\
\hline $\mathrm{D}_{4}$ & 3 & $1 / 3$ & 5 & 1 & 5 \\
\hline $\mathrm{D}_{5}$ & $1 / 3$ & $1 / 5$ & 3 & $1 / 5$ & 1 \\
\hline
\end{tabular}

Table 10. $\mathrm{C}_{6}$-D judgment matrix

\begin{tabular}{|c|c|c|c|c|c|}
\hline $\mathrm{C}_{6}$ & $\mathrm{D}_{1}$ & $\mathrm{D}_{2}$ & $\mathrm{D}_{3}$ & $\mathrm{D}_{4}$ & $\mathrm{D}_{5}$ \\
\hline $\mathrm{D}_{1}$ & 1 & 3 & 8 & 7 & 5 \\
\hline $\mathrm{D}_{2}$ & $1 / 3$ & 1 & 6 & 5 & 3 \\
\hline $\mathrm{D}_{3}$ & $1 / 8$ & $1 / 6$ & 1 & $1 / 3$ & $1 / 5$ \\
\hline $\mathrm{D}_{4}$ & $1 / 7$ & $1 / 5$ & 3 & 1 & $1 / 3$ \\
\hline $\mathrm{D}_{5}$ & $1 / 5$ & $1 / 3$ & 5 & 3 & 1 \\
\hline
\end{tabular}

\subsubsection{The principle of index quantification}

Next, we will take the scale method proposed by T. L. Saaty as a tool, to judge the importance of the plans to the rules respectively. The score should meet the following standard shown in Table 11.

Table 11. Matrix index score standard

\begin{tabular}{|c|c|}
\hline Score & Meaning \\
\hline 1 & The $i$-th factor is as important as the $j$-th one \\
\hline 3 & The $i$-th factor is more important than the $j$-th one \\
\hline 5 & The $i$-th factor is more important than the $j$-th one obviously \\
\hline 9 & The $i$-th factor is more important than the $j$-th one strongly \\
\hline $2,4,6,8$ & The $i$-th factor is extremely important than the $j$-th one \\
\hline $\begin{array}{c}\text { The reciprocal of the } \\
\text { above numbers }\end{array}$ & $\begin{array}{c}\text { The comparison of the } i \text {-th and the } j \text {-th is between the above } \\
\text { levels }\end{array}$ \\
\hline $\begin{array}{c}\text { If the scale of the comparison of the } i \text {-th and the } j \text {-th factors is } a_{i j} \\
\text { the of the comparison of the } j \text {-th and the } i \text {-th factors is } 1 / a_{i j}, \text { that is } \\
\text { to say } a_{j i}=1 / a_{i i}\end{array}$ \\
\hline
\end{tabular}

5.2.2. Calculation of the weight of factors in the single criterion and consistency check

- Based on the judgment matrix, the weight of the factors can be obtained by using the root method as follows:

$$
G_{i}=n \sqrt{\prod_{j=1}^{n} a_{i j}}, i=1,2,3, \ldots, n .
$$

- By the normalization of $G_{i}$, can be defined

(2)

$$
\begin{gathered}
W_{i}=\frac{G}{\sum_{i=1}^{n} G_{i}}, i=1,2,3, \ldots, n, \\
W=\left(W_{1}, W_{2}, \ldots, W_{n}\right) .
\end{gathered}
$$

- Calculating Maximum Eigen Value

$$
\lambda_{\max }=\frac{1}{n} \sum_{i=1}^{n} \frac{(\mathrm{MW})_{i}}{W_{i}},
$$


MW refers to the new vector which is the product of $M$ and $W$, (MW) $)_{i}$ is the $i$-th factor of MW.

- Consistency check

Ordinary we use $\mathrm{CR}$, the consistency ratio index to check, it meets that

$$
\mathrm{CR}=\mathrm{CI} / \mathrm{RI} \text {. }
$$

In the formula, $\mathrm{CI}$ is the consistency index and RI stands for the average consistency ratio index, which is validated by a large amount of experiments. The value of RI is listed in Table 12.

Table 12. The value of RI

Table 12. The value of RI
\begin{tabular}{|c|l|c|c|c|c|c|c|c|c|}
\hline Matrix order & 1 & 2 & 3 & 4 & 5 & 6 & 7 & 8 & 9 \\
\hline RI & 0.00 & 0.00 & 0.58 & 0.90 & 1.12 & 1.24 & 1.32 & 1.41 & 1.45 \\
\hline
\end{tabular}

\subsection{The application of AHP}

According to the calculating model above given, with the matrix for the initial factors, through the genetic algorithm global search given in Fig. 1 of the model of the first layer of the specific index, weights are as follows:

$$
\begin{array}{lll}
W_{1}^{C}=(0.6144,0.1172,0.2684)^{\mathrm{T}}, & \lambda_{\max }=3.0737, \quad C I=0.0369, & \mathrm{CR}=0.0636<0.1 . \\
W_{2}^{C}=(0.2790,0.0719,0.6491)^{\mathrm{T}}, & \lambda_{\max }=3.0650, \quad C I=0.0325, \quad C R=0.0560<0.1 .
\end{array}
$$

The criterion level of the specific weight values is as follows:

$$
\text { C onsuming: } \quad W_{1}^{D}=(0.1073,0.0389,0.2967,0.0646,0.4925)^{\mathrm{T}} \text {, }
$$

$\lambda_{\text {max }}=5.3677, \mathrm{CI}=0.0919, \mathrm{CR}=0.0821<0.1$.

Human: $\quad W_{2}^{D}=(0.1327,0.0652,0.4966,0.2701,0.0354)^{\mathrm{T}}, \quad \lambda_{\max }=5.3027$, $\mathrm{CI}=0.0757, \quad \mathrm{CR}=0.0676<0.1$.

C a p ita l: $\quad W_{3}^{D}=(0.1353,0.2487,0.5063,0.0736,0.0361)^{\mathrm{T}}, \quad \lambda_{\max }=5.2960$, $\mathrm{CI}=0.0740, \quad \mathrm{CR}=0.0661<0.1$.

Benefited Users: $\quad W_{4}^{D}=(0.1365,0.4775,0.0364,0.2779,0.0717)^{\mathrm{T}}$, $\lambda_{\max }=5.3272, \mathrm{CI}=0.0818, \mathrm{CR}=0.0730<0.1$.

Convenience: $\quad W_{5}^{D}=(0.1263,0.4896,0.0443,0.2663,0.0735)^{\mathrm{T}}, \quad \lambda_{\max }=5.3104$, $\mathrm{CI}=0.0776, \quad \mathrm{CR}=0.0693<0.1$.

U p g r a d ing: $W_{6}^{D}=(0.5073,0.2605,0.0354,0.0648,0.1320)^{\mathrm{T}}, \quad \lambda_{\max }=5.2752$, $\mathrm{CI}=0.0688, \quad \mathrm{CR}=0.0614<0.1$.

When $\mathrm{CR}<0.1$, the matrix is consistent, so we can get that the weight values above are all reasonable.

This paragraph is illustration of the above result. Table 12 shows that the leadership attention is the main criteria in "upgrading", and the "time consuming" is the second. Finally, to construct the whole model on the city informatization evaluation index through the system, we can get all the indices of the specific weight values. For detailed data see Table 13. 
Table 13. Informatization evaluation index system

\begin{tabular}{|c|c|c|}
\hline Primary index B & Second Index C & Weight $W$ \\
\hline \multirow{3}{*}{ Cost $B_{1} \quad(0.5)$} & Time Consuming $\mathrm{C}_{1}(0.6144)$ & 0.3072 \\
\hline & Human $\mathrm{C}_{2}(0.1172)$ & 0.0286 \\
\hline & Capital $\mathrm{C}_{3}(0.2684)$ & 0.1342 \\
\hline \multirow{3}{*}{ Uitlity $B_{2}(0.5)$} & Benefited Users $\mathrm{C}_{4}(0.2790)$ & 0.1395 \\
\hline & Convenience $\mathrm{C}_{5}(0.0719)$ & 0.0360 \\
\hline & Upgrading $\mathrm{C}_{6}(0.6491)$ & 0.3246 \\
\hline
\end{tabular}

The value of a plan is decided by eight indices, the score of the plan can be calculated by

$$
X_{i}=\frac{1}{2} \sum_{j=1}^{3} W_{j i}^{D} W_{1 j}^{C}+\frac{1}{2} \sum_{j=4}^{6} W_{j i}^{D} W_{2 j}^{C},
$$

$i$ is the serial number of the plan $i=1,2, \ldots, 5 ; X_{i}$ refers to the value of the $i$-th plan; $W_{j i}^{D}$ is the weight value of the $i$-th plan to the $j$-th rule; $W_{1 j}^{C}$ and $W_{2 j}^{C}$ are the weight of the $j$-th rule to the primary index. After calculation we can get the results:

$$
X=(0.2471,0.2179,0.2064,0.1149,0.2137)^{\mathrm{T}} .
$$

It is not hard to see from the data, that among all plans plan A is the best with respect to the criterion we insist.

The plans have been proposed to promote the construction of informatization, this part is the numerical analysis of the plans, which can help the researchers and decision makers to seize the key point and value the strategy, using the set-valued iteration method to ascertain the significance of the five plans to the construction of the city informatization in practice.

\section{Conclusion}

To sum up, the paper provides a more precise and scientific method for the quantitative study of the evaluation index system for city informatization. The establishment of the index system laid a solid foundation for improving the level of China's city informatization. The informatization evaluation index system established through AHP pays more attention to upgrading and time consuming. To this criterion, choosing a particular industry or field of the city as an information entry point will be the best plan which will bring most power to city informatization.

Through city informatization construction, coordinated and harmonious relationship between human beings and the environment particularly play a positive role in improving the city's business, transportation, education, health care, law and order, and community services, promoting sustainable development between urban economy and society. Using AHP can not only build a clear hierarchical model, but also help us achieve scientific, equitable orientation in the results.

Eventually, along with the realization of the city informatization, two points should be taken into account: the relationship between the city informatization construction and urban sustainability and controlling the negative effects at a 
relatively low level. It is related not only to urban material recycling in the information society, but also to the disposal of the new pollution sources in it, such as sound, light, electricity, information and electronic waste. In summary, we should use the point of systems engineering to guide the construction of city informatization.

\section{References}

1. C h e n, J. H. Information, Industrial Development and Urban Spaces Responding. Beijing, Social Sciences Academic Press, 2010, 38-40.

2. P e n g, D., D. H. L i n, H. Y. S h e n g. Digital City Shanghai: Concepts, Foundations, and Current State - In: Lecture Notes in Computer Science Digital Cities III, Information Technologies for Social Capital: Cross-Cultural Perspectives. Berlin, 2005, 141-165.

3. Gou, Z. W. Actively and Steadily Push Forward the City Informatization. - China Computer Users, Vol. 17, 2002, No 29, 13-14.

4. Ke, X. S., X. W. Li. Research on the Development Strategy of Web MIS in China. - In: Proceedings of the International Conference on Telecommunications, Publishing House of Electronics Industry, Beijing, 2002, 57-60.

5. K i m, S., K. C h o. Achieving Administrative Transparency through Information Systems: A Case Study in the Seoul Metropolitan Government. - In: Lecture Notes in Computer Science, Electronic Government: 4th International Conference, Springer Verlag, Berlin, 2005, 113-123.

6. L e viss, J., et al. - In: Proceedings of 16th IEEE Symposium on Computer-Based Medical Systems, CBMS 2003, IEEE, Los Alamitos, 2003, 3-5.

7. L u, X. Study on Promote the Construction and Development of the "Digital Hubei". - In: 2011 International Conference on Multimedia Technology, ICMT’2011, IEEE Computer Society, Piscataway, 2011, 3678-3680.

8. P e n g, Y. F., X. S h e n. Commonly Used Methods in Economic Management. Beijing, Economy Management Publishing House, 2011, 187-193.

9. System Application Office. City Informatization Before Making any Decisions. - China Computer Users, Vol. 21, 2002, No 10, 8-12.

10. Tong, X. J. Information and Digital Tactics of City. Liaoning, Northeastern University Publication, 2008, 7-9.

11. W a n g, P. Innovate Between Urban Information and Governance Model. Shanghai, Xuelin Press, 2005, 13-15.

12. W u, S. W., G. Q. Y a n. Wisdom City Technology Leading Harmony. Hangzhou, Zhejiang University Press, 2010, 7-10.

13. Z h a n g, N. G. The China City Informatization Promotion Conference Held in Wuxi. - UPS Application, 2012, No 137, p. 65.

14. 2012 Chinese City Informatization Promotion Conference \& the 3th Chinese City informatization 50 Strong Conference. http://www.ciia.org.cn/xwzx/tpxw/201109/t20110927_31476.html

15. 2010Beijing Informatization Annual Report. http://www.bjeit.gov.cn/zwgk/ghjh/jhzj/201205/t20120517_24319.htm

16. Several Opinions on Accelerating the Depth of Fusion of Informatization and Industrialization. http://xxhs.miit.gov.cn/n11293472/n11295327/n11297143/13717979.html

17. The 12th Five-year Plan of the Capital Economy and Social Development for Hainan Province. http://www.hainan.gov.cn/data/news/2011/03/124176/ 